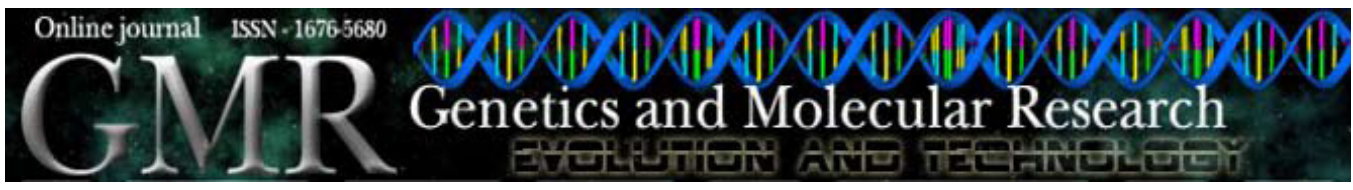

Thesis Abstract

\title{
Le(a-b-) phenotype: potential risk factor for infection by the RH strain of Toxoplasma gondii in pregnancy
}

\author{
F. Nakashima \\ 2010. Programa de Pós-Graduação em Genética, Departamento de Biologia, \\ Universidade Estadual Paulista "Julio de Mesquita Filho", São José do Rio \\ Preto, SP, Brasil. Master's thesis. Supervising Prof.: Dr. Luiz Carlos de Mattos
}

The Lewis histo-blood group system is characterized by the expression of the $\mathrm{Le}^{\mathrm{a}}$ and $\mathrm{Le}^{\mathrm{b}}$ antigens in the gastrointestinal tract, whose synthesis results in interactions between $\alpha 2$-L-fucosyltransferase (FUTII) and $\alpha 3 / 4$-L-fucosyltransferase (FUTIII) enzymes coded by the FUT2 (19q.13.3) and FUT3 (19p13.3) genes. FUTII and FUTIII fucosylate the type 1 oligosaccharide precursor $(\mathrm{Gal} \beta 1 \rightarrow 3 \mathrm{NAcGlc} \beta 1 \rightarrow 3-\mathrm{R})$ at distinct positions to form $\mathrm{H}$ type 1 $($ Fuc $\alpha 1 \rightarrow 2$ Gal $\beta 1 \rightarrow 3 N A c G l c \beta 1 \rightarrow 3-R)$ and $\mathrm{Le}^{\mathrm{a}}(\mathrm{Gal} \beta 1 \rightarrow 3[\mathrm{Fuc} \alpha 1 \rightarrow 4] \mathrm{NAcGlc} \beta 1 \rightarrow 3-\mathrm{R})$ antigens, respectively. The fucosylation of $\mathrm{H}$ type 1 antigens by FUTIII results in the Le $\mathrm{e}^{\mathrm{b}}$ antigen (Fuc $\alpha 1 \rightarrow 2$ Gal $\beta 1 \rightarrow 3[$ Fuc $\alpha 1 \rightarrow 4]$ NAcGlc $\beta 1 \rightarrow 3-\mathrm{R}$ ). Thus, the presence of the FUTII and FUTIII enzymes leads to the expression of the $\operatorname{Le}(\mathrm{a}+\mathrm{b}+)$ phenotype, while the presence of only FUTIII allows the expression of the Le(a+b-) phenotype. The absence of the FUTIII enzyme leads to the expression of the Le(a-b-) phenotype, independent of the presence or absence of FUTII. Point mutations in FUT2 and FUT3 genes change the activity of these enzymes, impair the synthesis of $\mathrm{Le}^{\mathrm{a}}$ and $\mathrm{Le}^{\mathrm{b}}$ antigens, and contribute to the variability of Lewis phenotypes in the gastrointestinal tract. Toxoplasma gondii, an apicomplexan parasite that infects a large proportion of the world's population, utilizes the gastrointestinal tract as an infection route and seems to adhere to glycosylated molecules to invade human cells. These apparently independent events may be related. The aim of this study was to test the hypothesis that there is an association between the Lewis histo-blood group system and infection by $T$. gondii. Two hundred and nine serum samples collected from pregnant women were submitted to screening tests to detect anti-T. gondii antibodies, employing the indirect hemagglutination method. ELISA was utilized to identify IgG class anti-T. gondii antibodies specific for the RH strain. A hundred and ninety-five samples with concordant results for both methods were selected to form two groups: seropositive (G1) and seronegative (G2). The G428A mutation of the FUT2 gene, and T202C and C314T of the FUT3 gene, which allow inference of the gastrointestinal tract Lewis phenotypes, were identified using PCRRFLP and PCR-SSP methods, respectively. Among the 195 samples selected, 116 (59.5\%) were seropositive and $79(40.5 \%)$ were seronegative. In G1, 68 (58.6\%) were classified as $\operatorname{Le}(\mathrm{a}+\mathrm{b}+)$, 
$30(25.9 \%)$ as $\mathrm{Le}(\mathrm{a}+\mathrm{b}-)$, and $18(15.5 \%)$ as $\mathrm{Le}(\mathrm{a}-\mathrm{b}-)$, and in G2, $67(84.8 \%)$ were classified as $\mathrm{Le}(\mathrm{a}+\mathrm{b}+), 12(15.2 \%)$ as $\mathrm{Le}(\mathrm{a}+\mathrm{b}-)$, and $0(0 \%)$ as Le $(\mathrm{a}-\mathrm{b}-)(\mathrm{P}<0.0001)$. The Le(a-b-) phenotype is associated with a high risk of RH strain $T$. gondii infection when compared with the $\mathrm{Le}(\mathrm{a}+\mathrm{b}+)$ $[\mathrm{P}=0.0001 ; \mathrm{OR}=36,460 ; 95 \% \mathrm{CI}=2.152-617,680]$ and $\mathrm{Le}(\mathrm{a}+\mathrm{b}-)$ phenotypes $[\mathrm{P}=0.0118$; OR $=15,165 ; 95 \% \mathrm{CI}=0.8463-271,710]$. The Le $(\mathrm{a}+\mathrm{b}-)$ phenotype showed a higher risk compared to the $\mathrm{Le}(\mathrm{a}+\mathrm{b}+)$ phenotype $[\mathrm{P}=0.0206 ; \mathrm{OR}=2463 ; 95 \% \mathrm{CI}=2463-5214]$. The results suggest that the Le(a-b-) phenotype is strongly associated with a greater risk of infection by the RH strain of $T$. gondii compared to the other phenotypes. It is possible that the absence of fucosylation of the type 1 oligosaccharide precursor as well as the variations in the structures of the $\mathrm{Le}^{\mathrm{a}}$ and $\mathrm{Le}^{\mathrm{b}}$ antigens influence susceptibility to infection by this parasite.

Key words: Toxoplasmosis; FUT2; FUT3; Toxoplasma gondii;

High-risk pregnancy; Lewis histo-blood group system

Research supported by CAPES, BAP-FAMERP 2007-2008, and CNPq. 